\title{
Reflections on Six Decades of Research on Adolescent Behavior and Development
}

\author{
Richard Jessor (10 ${ }^{1}$
}

Received: 3 January 2018 / Accepted: 5 January 2018 / Published online: 22 January 2018

(c) Springer Science+Business Media, LLC, part of Springer Nature 2018

\begin{abstract}
These reflections, spanning six decades of involvement with developmental behavioral science, report on several salutary trends that have shaped that field of social inquiry, e.g., its increasingly trans-disciplinary character. They also take note of some of its enduring limitations, e.g., its failure to engage with theory. In addition, the reflections confront some current issues, such as the widespread stereotyping of adolescents as risk takers, and the growing recourse to reductionist explanation. On balance, however, developmental behavioral science can be seen in retrospect as having evolved in a decidedly positive direction. Clearly, it has yielded a firmer grasp on adolescent behavior and development.
\end{abstract}

Keywords Adolescent development $\cdot$ Developmental behavioral science $\cdot$ Problem behavior theory $\cdot$ Risk behavior . Qualitative method $\cdot$ Reductionism

A recent experience of having to organize the body of my work on adolescent behavior and development since the late 1950s (Jessor 2016, 2017a, b) stimulated some overall impressions about the burgeoning field of developmental behavioral science (Jessor 1993). This account of those impressions-about my own work as well as the work of other scholars-while not exhaustive by any means, takes note of several salutary trends, calls attention to a few important shortcomings, and engages with some current issues in the field.

In regard to salutary trends, an overriding impression is that the field has, indeed, become more truly developmental, relying far more on time-extended or longitudinal designs than was the practice early on. This greater reliance on studying how the same young people grow and change over time has replaced an earlier reliance on inferring growth and change from differences between age cohorts. In addition to the greater developmental attention to intra-individual change, there has been increased attention to assessing concomitant change in the predictors or co-variates of that intra-individual change over the same time segment (Jessor

Richard Jessor

jessor@colorado.edu

1 Institute of Behavioral Science, University of Colorado, Boulder, CO 80309, USA and Jessor 1977). That is to say, there is increased awareness that a more compelling understanding of developmental change requires simultaneously demonstrating theoretically-consonant or theoretically-parallel change in its determinants as well.

Another important trend in the field of developmental behavioral science is that it has become increasingly inter-or trans-disciplinary. Whereas earlier developmental studies tended to focus on individual/ psychological variation, while eliding attention to variation in the social environment, or focused on the latter, while eliding attention to individual variation, more recent studies have tended to encompass variation in both person and context, engaging -in the very same study-explanatory concepts not only from psychology but also from the social disciplines.

Notable also as an important trend has been the enlargement in developmental research of what constitutes a satisfactory explanatory objective. In contrast to earlier studies that sought to predict or explain single behaviors (e.g., aggression), or single attitudes (e.g., self-esteem), or single beliefs (e.g., internal control), or to engage single contexts (e.g., the peer group, or the family, or the school), more recent developmental work has sought to account for more comprehensive explanatory objectives, objectives that subtend those separate domains in ways that capture a larger sense of the individual-in-context, concepts such as lifestyle that constitute an individual's way of thinking, believing, and behaving across contexts, and represent an adolescent's 
overall way of being in the world. Reliance in developmental research on single concepts, whether behaviors or beliefs or attitudes or contexts, can be expected to yield only highly constrained, even impoverished, understanding of individuality and of individual development.

Developmental research has also become far more problem-focused than in earlier years, responding, at least in part, to Kurt Lewin's insistence (1951) that theory-guided inquiry can be carried out not just in laboratories but in the full social context in which it occurs, and that, indeed, contextually-situated findings yield greater external validity than those that are laboratory-based. Concern with social problems in adolescence and youth, such as drug use, violence, obesity, poverty, etc., has animated considerable developmental research in recent decades, has led to innovative research designs, e.g., predicting variation in time of onset or initiation of problem behaviors, and has generated innovative explanatory concepts, e.g., the notion of "transition proneness," that is, a readiness to make an age-graded developmental change. This invigorated problem focus has been another important contribution to developmental behavioral science.

In relation to the greater focus on problem behaviors, there has been a broadening consensus that problem behaviors in adolescence and young adulthood come in clusters, that is, that they tend to co-vary, to have common determinants, and, indeed, to constitute a "problem behavior syndrome" (Jessor and Jessor 1977). This recognition has transformed what previously had been specializations by developmental scholars in particular problem behaviors, e.g., delinquency, or drinking behavior, or tobacco use, or precocious sexual activity, etc., into greater acceptance of the obligation in developmental research to engage the larger pattern of involvements across those previously segmented domains. [For a similar issue in health behavior research, the report of a recent meeting sponsored by the National Cancer Institute (Klein et al. 2016) stated: “... research programs often examine single health behaviors without a systematic attempt to integrate knowledge across behaviors." (p. 1); and concluded that "Integrating knowledge across behavioral domains is a public health imperative." (p. 6).]

Another salutary trend has been the growing recognition that a commitment to understanding adolescent problem behavior is not incompatible with a concern for understanding positive youth development but, indeed, is essential to the latter. Initially presented as an antidote to a perceived over-emphasis on problem behavior in adolescence, the positive youth development movement sought to counter by emphasizing, instead, adolescent strengths and assets. An unfortunate antinomy was established, thereby, between research on adolescent problem behavior and research on adolescent assets. That oppositional division was unhelpful in that it could yield only a partial understanding of adolescence and adolescent development; after all, problems and assets co-exist in every adolescent, and to privilege one at the expense of the other is to compromise a broader understanding. Recently there have been signs of a growing reconciliation between the two research constituencies and a mutual recognition that a firm grasp on adolescence and youth requires attention to both problems and assets—and to how they relate-and that comprehensive interventions designed to prevent the former and promote the latter require strategies tailored to each (Jessor and Turbin 2014).

With regard to method, the long-term, seemingly intractable opposition between quantitative and qualitative approaches to research appears to have been tempered or mitigated in recent decades, and research projects are increasingly employing both methods. A salutary outcome of the openness of the post-positivist era in social inquiry, it reflects a growing recognition of the compelling logic of methodological pluralism and of reliance on mixed methods and on their convergence. It also has entailed a closer examination of the epistemological foundations of both approaches, with one author claiming "...the distinction between qualitative and quantitative is of limited use and, indeed, carries some danger" (Hammersley 1992, p. 159), and another stating that "...all studies have an "ethnographic" component embedded in them, even if ethnography was not done" (Weisner 1996). In a relevant volume (Jessor et al. 1996) reporting on a conference examining the distinctive role of qualitative research on human development, the consensus that was reached was that "...qualitative and quantitative methods of social inquiry, though often asking different kinds of questions, share a common epistemological foundation and a common philosophy of science" (Jessor 1996, p. 264). Happily, we are now past the time of awarding honorific status to particular methods, whether qualitative or quantitative, and increasingly see methods simply as handmaidens to theory and problems.

Lastly, a salutary trend also worth noting is the greater interest in adolescent health and in the role that it plays in development. There has been an assimilation of the interest in problem behaviors with an interest in health behaviors since many of what are termed problem behaviors are, at the same time, health-compromising behaviors. It has become evident that health behaviors also cluster, as do problem behaviors, and that involvements in health-promoting behaviors relate inversely to involvements in problem behavior. The broader rubric of behavioral health emerged some time ago (e.g., Matarazzo et al. 1984) to refer to all those behaviors that are relevant to variation in adolescent health, including problem behaviors that can compromise health, regular exercise and healthy diet that can promote health, safety behaviors such as seatbelt use that can protect 
health, etc. This increased attention to the role of health in adolescent behavior and development has obvious reverberations for intervention efforts to advance positive, prosocial development more generally.

With regard to shortcomings or disappointments, my overriding impression is that theory in general, and theories of the middle range (Merton 1957) especially, have played only a limited role in developmental behavioral science over recent decades. This impression is buttressed by a perceptive comment on contemporary research on adolescent development by a well-known developmental scholar; he laments that: "...the majority of studies are effectively atheoretical, with the occasional theoretical gloss added to provide a patina of respectability rather than to articulate an explicit framework in which the research was grounded" (Lamb 2015, p. 117).

Beyond possibly providing that "patina of respectability" - and far more important, of course-engaging with theory provides the foundation for explanation at what Kurt Lewin long ago termed the genotypic level (Lewin 1935), the level of underlying, causal constructs or determinants, in contrast to the phenotypic, observable, or descriptive level. It is theory that enables generality of findings across cultures and local, national, or international settings that differ greatly at the descriptive level, and across persons who vary in age, gender, ethnicity, social status, and national origin, among other attributes. The impact of genotypic, theoretical constructs such as social support or social control, for two examples, on adolescent behavior or experience should be invariant, whether from an older sib in Chicago, or a parent in Italy, or a teacher in Iran (Jessor 2008). Engaging theory in developmental research also permits the logical derivation of measures and procedures from the theory, thereby endowing them with construct validity at the outset of the research. Greater engagement with theory, its development and application, increases the likelihood of developmental research findings that will have both generality and robustness.

Another issue of concern has been what appears to be something of a resurgence of 20th-century reductionism (Jessor 1958) in developmental behavioral science. For one example, there has been considerable recent attention to the so-called "immature adolescent brain," the still-developing frontal lobes especially, in accounting for adolescent risk behavior. For another, heavy involvement with substances, whether alcohol or other drugs, is increasingly referred to as an "addiction," and the latter has recently been deemed a "brain disease." More broadly, there has been growing engagement with genetics in research on adolescence. Expanding developmental behavioral science to engage with and accommodate brain science and genetics can, of course, enlarge the explanatory network and constitute thereby an important scientific achievement. It is only when recourse to the brain and to genetics is considered to provide more fundamental or causal or basic explanation that it becomes problematic and relies upon an archaic notion of a hierarchy of the sciences. Not only are the mechanisms that could link brain and genes to behavior and experience not yet established, but the amount of variance in behavior and experience they account for remains small, especially in contrast to that of the psychosocial level of analysis. It would be unfortunate, therefore, if latter-day reductionist thinking in support of biological explanation were to divert attention from the quest for psychosocial understanding.

One more disappointing impression about the field is the continued and widespread employment of the concept of risk taking behavior rather than risk behavior in studies of adolescent engagement in the various problem behaviors. It has been nearly three decades since I argued-unsuccessfully as it has turned out-that the use of that term yielded stereotypical characterizations of adolescents as risk takers, an unfortunate tautology, and that it should be dropped from the scientific vocabulary (Jessor 1991). The fact is, of course, that many of the behaviors that adolescents engage in do, indeed, put them at risk for negative consequences, whether for dropping out of school, or getting pregnant, or becoming involved with the justice system, or failing to meet their parents' expectations. But the fact that risk is entailed in engaging in those behaviors does not mean that the adolescent is aware of that risk, has sought that risk, or engaged in the behavior because of the risk, that is, that the adolescent by engaging in behaviors that entail risk is, thereby, a risk taker. Adults who drive a car to work or for shopping engage in a behavior that clearly carries risk for accidents, but we do not refer to them as risk takers just because of that. It would seem best for developmental scientists to dispense with the concept of risk taking behavior (except, of course, for those behaviors, e.g., drag racing or rock climbing, perhaps, where risk is deliberately sought) in favor of the neutral concept of risk behavior. The latter term would make clear that accounting for adolescent engagement in risk behavior requires the very same kind of complex search for explanation as does adolescent engagement in any other category of behavior, without needing to rely on the simplistic and tautological explanation that adolescents are risk takers.

Looking back over these past six decades, it is my overall impression that developmental behavioral science has pursued a decidedly fruitful direction, achieving a transdisciplinary grasp on adolescence and bringing illumination to the process of development and change that characterizes that segment of the life course. It has been an enduring source of excitement to have been a participant in and a long-time contributor to that enterprise. With regard to the latter, our development of a middle-range theory known as Problem Behavior Theory (Jessor 2014, 2016, 
$2017 \mathrm{a}, \mathrm{b})$, in collaboration with many colleagues and students over the decades, may be the most significant contribution. The theory's development has been responsive to most of the salutary trends noted in these reflections. My hope now is that those trends will continue and serve as imperatives for the next generation of developmental behavioral scientists.

\section{Compliance with ethical standards}

Conflict of Interest The authors declare that they have no conflict of interest.

\section{References}

Hammersley, M. (1992). What's wrong with ethnography? Methodological explorations. London: Routledge.

Jessor, R. (1958). The problem of reductionism in psychology. Psychological Review, 65(3), 170-178.

Jessor, R. (1991). Risk behavior in adolescence: A psychosocial framework for understanding and action. Journal of Adolescent Health, 12(8), 597-605.

Jessor, R. (1993). Successful adolescent development among youth in high-risk settings. American Psychologist, 48(2), 117-126.

Jessor, R. (1996). Ethnographic methods in contemporary perspective. In R. Jessor, A. Colby \& R. A. Shweder (Eds.), Ethnography and human development: Context and meaning in social inquiry. Chicago, IL: University of Chicago Press.

Jessor, R. (2008). Description versus explanation in cross-national research on adolescence. Journal of Adolescent Health, 43(6), $527-528$.

Jessor, R. (2014). Problem Behavior Theory: A half-century of research on adolescent behavior and development. In R. M. Lerner, A. C. Petersen, R. K. Silbereisen \& J. Brooks-Gunn (Eds.), The developmental science of adolescence: History through autobiography. New York, NY: Psychology Press.

Jessor, R. (2016). The origins and development of Problem Behavior Theory: The collected works of Richard Jessor, Volume 1. New York, NY: Springer International Publishing.

Jessor, R. (2017a). Problem Behavior Theory and adolescent health: The collected works of Richard Jessor, Volume 2. New York, NY: Springer International Publishing.

Jessor, R. (2017b). Problem Behavior Theory and the social context: The collected works of Richard Jessor, Volume3. New York, NY: Springer International Publishing.
Jessor, R., Colby, A. \& Shweder, R. A. (Eds.), (1996). Ethnography and human development: Context and meaning in social inquiry. Chicago, IL: University of Chicago Press.

Jessor, R., \& Jessor, S. L. (1977). Problem behavior and psychosocial development: A longitudinal study of youth. New York, NY: Academic Press.

Jessor, R., \& Turbin, M. S. (2014). Parsing protection and risk for problem behavior versus pro-social behavior among US and Chinese adolescents. Journal of Youth and Adolescence, 43, 1037-1051.

Klein, W. M. P., Grenen, E. G., O'Connell, M., Blanch-Hartigan, D., Chou, W.-Y. S., Hall, K. L. et al. (2016). Integrating knowledge across domains to advance the science of health behavior: Overcoming challenges and facilitating success. Translational Behavioral Medicine, 7, 1-8.

Lamb, M. E. (2015). Reflections on the evolution of theory in developmental science: A commentary on Lerner, Johnson, and Buckingham. Journal of Family Theory \& Review, 7(2), 115-117.

Lewin, K. (1935). A dynamic theory of personality: Selected papers. New York, NY: McGraw-Hill.

Lewin, K. (1951). Field theory in social science: Selected theoretical papers. New York, NY: Harper \& Row.

Matarazzo, J. D., Weiss, C. M., Herd, J. A., Miller, N. E. \& Weiss, S. M.(Eds.), (1984). Behavioral health: A handbook of health enhancement and disease prevention. New York, NY: Wiley.

Merton, R. K. (1957). Social theory and social structure. (Rev. and enl. edit.) New York, NY: Free Press.

Weisner, T. S. (1996). Why ethnography should be the most important method in the study of human development. In R. Jessor, A. Colby \& R. A. Shweder (Eds.), Ethnography and human development: Context and meaning in social inquiry. Chicago, IL: University of Chicago Press.

Richard Jessor is currently Distinguished Professor of Behavioral Science and Research Professor at the University of Colorado, Boulder. He is also Professor Emeritus of Psychology. One of the founders of the university's Institute of Behavioral Science in 1959, he served as its Director from 1980 to 2001. From 1987 to 1997, he also directed the MacArthur Foundation Research Network on Successful Adolescent Development among Youth in High-Risk Settings. In 2005, he received the Outstanding Achievement in Adolescent Medicine Award from the Society for Adolescent Medicine. His areas of research include adolescent and young adult development, the social psychology of risk behavior, social determinants of behavioral health, and psychosocial aspects of poverty. 